ORIGINAL RESEARCH

\title{
Differences in Rates of High-Value and Low-Value Care Between Community Health Centers and Private Practices
}

\author{
Carlos Irwin A. Oronce, $M D, M P H^{1,2}$ and Robert J. Fortuna, MD, MPH $H^{3,4,5}$ \\ IVA Greater Los Angeles Healthcare System, Los Angeles, CA, USA; ${ }^{2}$ National Clinician Scholars Program and the Division of General Internal \\ Medicine and Health Services Research, University of California, Los Angeles, CA, USA; ${ }^{3}$ Department of Medicine, University of Rochester Medical \\ Center, Rochester, NY, USA; ${ }^{4}$ Department of Pediatrics, University of Rochester Medical Center, Rochester, NY, USA; ${ }^{5}$ Center for Primary Care, \\ Culver Medical Group, University of Rochester Medical Center, Rochester, NY, USA.
}

BACKGROUND: Community health centers (CHCs) are an integral part of the health care safety net. As health systems seek to improve value, it is important to understand the quality of care provided by CHCs.

OBJECTIVE: To evaluate the performance of CHCs compared with private practices on a comprehensive set of high-value and low-value care measures.

DESIGN: This cross-sectional study used data from the National Ambulatory Medical Care Survey from 2010 through 2012. We compared CHCs with private practices using logistic regression models that adjusted for age, sex, race/ethnicity, insurance, number of chronic illnesses, rural versus urban location, region of country, and survey year.

SETTING/PARTICIPANTS: We included outpatient visits to generalist physicians at either $\mathrm{CHCs}$ or private practices by patients 18 years and older.

MAIN MEASURES: We examined 12 measures of highvalue care and 7 measures of low-value care.

RESULTS: A total of 29, 155 physician visits, representing 584,208,173 weighted visits, from 2010 through 2012 were included. CHCs were more likely to provide highvalue care by ordering beta-blockers in CHF (46.9\% vs. 36.5\%; aOR 2.56; 95\%CI 1.18-5.56), statins in diabetes (37.0\% vs 35.5\%; aOR 1.35; 95\%CI 1.02-1.79), and providing treatment for osteoporosis (35.7\% vs $23.2 \%$; aOR 1.77 ; 95\%CI 1.05-3.00) compared with private practices. CHCs were more likely to avoid low-value screening EKGs (98.7\% vs. 88.0\%; aOR 11.03; 95\%CI 2.67-45.52), CBCs (75.9\% vs. 65.7\%; aOR 1.72; 95\%CI 1.18-2.53), or urinalyses (86.0\% vs. 80.5\%; aOR 1.87; 95\%CI 1.11-3.14) during a general medical exam. CHCs were also less likely to prescribe antibiotics for a URI (48.3\% vs. 63.1\%; aOR 0.59; 95\%CI 0.40-0.88).

CONCLUSIONS: On a number of high-value and lowvalue measures of care, CHCs performed similar to or better than private practices. As healthcare delivery reforms continue to progress, CHCs are well positioned to provide high-value healthcare.

KEY WORDS: high-value care; low-value care; quality of care; community health centers; federally qualified health centers.

This study was presented as an oral presentation at the Society of General Internal Medicine Annual Meeting, Denver CO, 11-14 April 2018.

Received January 29, 2019

Revised September 17, 2019

Accepted October 8, 2019

Published online November 19, 2019
J Gen Intern Med 35(4):994-1000

DOI: $10.1007 / \mathrm{s} 11606-019-05544-\mathrm{z}$

(c) Society of General Internal Medicine 2019

\section{BACKGROUND}

Community health centers $(\mathrm{CHC})$ are comprehensive primary care clinics located in underserved areas of the country and serve a unique mission to provide care for all patients regardless of income or insurance status. CHCs include both federally qualified health centers (FQHCs) and FQHC look-alike clinics which meet the structural and organizational requirements of $\mathrm{FQHCs}$ but do not receive the same federal grants. Since their establishment in the 1960s, CHCs have grown to include nearly 1,400 practices nationally that care for more than 27 million people. ${ }^{1}$

CHCs are largely funded through a prospective payment system set by Medicaid in addition to federal grants that cover the costs of caring for the uninsured. The latter includes Section 330 grants of the Public Health Act, which confers the FQHC designation. In 2015, federal funding for CHCs totaled \$21 billion, with 44\% through Medicaid, 18\% from Section 330 grants, and the remainder coming from Medicare, commercial insurers, self-pay, and various grants. ${ }^{2}$ Given the significant federal funding allocated to CHCs, policymakers have long been interested in understanding the quality of care they provide.

Prior work has arrived at differing conclusions regarding the provision of high-value care and the avoidance of low-value care at $\mathrm{CHCs}$ compared with non-CHC practices. High-value care describes the delivery of guideline-concordant care that improves health, avoids harms, and eliminates wasteful practices. ${ }^{3}$ This includes preventative care, which has been shown to be delivered at higher rates at CHCs compared with that to nonCHCs. ${ }^{4}$ The only national study to examine high-value chronic disease measures demonstrated that $\mathrm{CHCs}$ had higher rates of adherence on process measures for coronary artery disease and congestive heart failure compared with private practices. ${ }^{5}$

Low-value care encompasses the overutilization of services that provide marginal or unknown benefit to patients. Such measures of low-value care, which include unnecessary testing and preventable utilization of hospital settings, have received greater attention due to efforts like the Choosing Wisely campaign from the American Board of Internal Medicine 
(ABIM) ${ }^{6}$ Prior studies that have examined rates of potentially preventable hospitalizations (also called ambulatory caresensitive admissions) among patients at CHCs compared with those at non-CHCs were limited in size and scope, and have yielded divergent results. ${ }^{7-9}$

Other recent works examining safety net providers, more broadly defined than CHCs, found they provided comparable rates of low-value care as non-safety net providers nationally. ${ }^{10} \mathrm{CHCs}$ are unique within the safety net, however, due to the statutory requirements tied to their funding. Under the purview of Section 330 of the Public Health Act, CHCs are governed by a patient majority board and must provide services according to local needs. ${ }^{11}$ These additional requirements and community responsibilities may influence how they spend their scarce resources. The rates of low-value care within $\mathrm{CHCs}$ in particular remain unclear.

As value-based health reform continues to grow in scope, our study builds on this prior work and aims to compare the performance of CHCs with that of private practices on a comprehensive set of high-value and low-value measures. We employ a national cross-sectional survey previously used to describe the delivery of health services in the USA.

\section{METHODS}

\section{Data Source and Study Design}

We used publicly available data from the National Ambulatory Medical Care Survey (NAMCS) from 2010 through 2012. NAMCS is a nationally representative survey of non-federal office-based clinicians that is conducted annually by the National Center for Health Statistics (NCHS). NAMCS uses a 3stage probability sampling design based on geographic area (also called primary sampling units or PSUs), physician practices within PSUs, and patient visits within the practice. Within the practice, each physician is randomly assigned to a 1week reporting period. During this period, US Census Bureau interviewers record a systematic random sample of visits. Visits are then weighted to national estimates of ambulatory care based on the inverse probability of selection at each stage of the sampling design. A comprehensive description of the methods used for data collection, sampling, and weighting in NAMCS is available at https://www.cdc.gov/nchs/ahcd/ahcd questionnaires.htm.

Between 2006 to 2012, the NCHS collected an additional sample of visits to community health center sites. This included visits to $\mathrm{FQHCs}$, FQHC look-alikes, and Urban Indian FQHCs. ${ }^{12}$ We selected the years 2010-2012, which were the most recent years available at the time of analysis, to provide a baseline sample of visits coinciding with the start of the national Choosing Wisely campaign, as well as delivery system reforms under the Affordable Care Act (ACA). Response rates from $\mathrm{CHCs}$ ranged from $76.1 \%$ in 2011 to $81.3 \%$ in 2012. The NCHS evaluated for non-response bias at both physician and visit levels. Additional details regarding sampling techniques and response rate are available online.

Our analysis was conducted at the visit level and included all visits from patients 18 years of age and older to primary care physicians who met the inclusion criteria. The inclusion criteria included the receipt of high-value or low-value care as described below. Primary care physicians included general internists, general physicians, and family physicians. Nonphysician clinicians, such as nurse practitioners and physician assistants, were not included since there were differences in how they were sampled prior to the 2012 survey year. We limited analyses to private practices and community health centers only.

\section{Definitions}

$\mathrm{CHCs}$ were defined as $\mathrm{FQHCs}$ receiving Section 330 funding, FQHC look-alikes, which applied for but did not receive Section 330 funding, and Urban Indian Health Service clinics. CHCs were identified using data from the Health Resources and Services Administration's Bureau of Primary Health Care and the Indian Health Service.

Private practices were defined as clinics that were in the solo or group practice setting. Hospital-based outpatient clinics, which are only available through the National Hospital Ambulatory Care Survey, were not included.

\section{Primary Outcomes}

Consistent with prior studies and guidelines, our outcomes encompassed the delivery of high-value and low-value care for common conditions in the primary care setting. We examined twelve measures of high-value care, including prescriptions for (1) aspirin, (2) beta blockers, or (3) statins in coronary artery disease; prescriptions for (4) beta blockers and (5) angiotensin-converting enzyme (ACE) inhibitors or angiotensin receptor blockers (ARB) for congestive heart failure (CHF); (6) prescriptions for anticoagulants in atrial fibrillation; (7) prescriptions for antiplatelets in cerebrovascular disease; (8) prescriptions for statins in diabetes mellitus; (9) weight reduction counseling for patients with obesity; (10) tobacco cessation counseling; (11) treatment for depression; and (12) treatment for osteoporosis. ${ }^{5,10,13-16}$ The seven measures of low-value care include (1) antibiotic prescriptions for an upper respiratory infection (URI), (2) opioid prescriptions for headaches, (3) opioid prescriptions for back or neck pain, (4) ordering of a CT or MRI for back or neck pain, and avoidance of routine tests during a general medical exam in the absence of symptoms, including avoidance of (5) routine electrocardiography (ECG), (6) complete blood counts (CBC), and (7) urinalysis (UA). ${ }^{5}, 10,13,14,17-20$

Each measure was constructed as a weighted percentage stratified by $\mathrm{CHC}$ versus private practice, where receipt of the highvalue or low-value service was counted in the numerator. All clinical encounters that were eligible for the receipt of a highvalue or low-value service were included the denominator. In 
some cases, a clinical encounter could be counted under several measures. Prescriptions were identified using medication codes provided in NAMCS and the ordering of diagnostic tests was directly captured through distinct variables in the survey.

\section{Inclusion and Exclusion Criteria}

Inclusion criteria for eligible visits were derived from primary and secondary International Classification of Diseases, Ninth Revision (ICD-9) diagnostic codes, reason for visit codes, and the fourteen chronic illness comorbidities that are directly captured in the survey. This was based on prior literature and codes are included in the Appendix. Exclusions were based on the presence of clinical red flags (i.e., history of malignancy when MRI is ordered for back pain) or possible contraindications to receiving care (i.e., history of gastrointestinal bleeding when anticoagulant for atrial fibrillation is not prescribed). The percentage was calculated as a weighted percentage with $95 \%$ confidence intervals provided.

\section{Statistical Analysis}

We report clinical and demographic characteristics by site of care, comparing $\mathrm{CHCs}$ with private practices. To examine the association between site of care and performance on each highvalue and low-value care measure, we constructed multivariable logistic regression models combining data across all 3 years. The models adjusted for age, sex, race/ethnicity, insurance, number of chronic illnesses, rural versus urban status based on metropolitan statistical area, region of country, and survey year. Race/ethnicity was collapsed into the categories of nonHispanic white, non-Hispanic black, Hispanic/Latino, and other. Self-pay and no charge/charity were collapsed into uninsured, while dual-eligible patients were collapsed into the Medicaid category for insurance status. The total number of chronic illnesses is routinely measured in the survey and is extracted from the medical record and problem list.

We performed all analyses in SAS Version 9.2 using previously reported methods that account for the complex survey design, including disproportionate survey weights, the multistage sampling frame, and clustering within geographic units and physicians. ${ }^{21}$ Our analyses followed the NCHS requirements for deriving national estimates based on the absolute number of sampled visits and relative standard error. ${ }^{12}$

$95 \%$ confidence intervals are reported and 2 -sided $p$ values $<0.05$ were considered statistically significant.

\section{Ethical Approval}

The University of Rochester Research Subjects Review Board approved this study.

\section{RESULTS}

Between 2010 and 2012, a total of 29,155 unweighted visits, representing 584.2 million weighted visits nationally, met the inclusion criteria for at least one quality metric. A total of 37.6 million weighted visits were to community health centers and 546.6 million were to private practices. Patients seen at CHCs tended to be younger compared with those at private practices. CHCs were more likely to see patients who were African American, Hispanic/Latino, insured by Medicaid, and uninsured. Additionally, patients in rural areas and in the western geographic area of the USA were more likely to be seen at CHCs (Table 1).

We examined the performance of CHCs and private practices using both unadjusted and adjusted analyses. Within unadjusted analyses, performance on high-value measures was low across both $\mathrm{CHCs}$ and private practices, with neither performing higher than $70 \%$ on any measure. On one measure, CHCs had higher rates of treatment for osteoporosis $(35.7 \%$ vs $23.2 \%, p<0.01$, Table 2). Within unadjusted analyses, $\mathrm{CHC}$ had higher rates of avoidance of low-value screening EKGs and CBCs $(98.7 \%$ vs $88.0 \%, p<0.001 ; 75.9 \%$ vs $65.7 \%, p<$ 0.01 , Table 2). They also had lower rates of prescribing of antibiotics in low-risk upper respiratory tract infections (48.3\% vs $63.1 \%, p<0.001$, Table 2 ).

After adjustment for age, sex, race/ethnicity, insurance, number of chronic illnesses, rural versus urban status, region of country, and survey year, our multivariable models revealed that $\mathrm{CHCs}$ performed better than private practices on additional measures with respect to high-value and low-value care. Figure 1 depicts the provision of high-value care. CHCs were

Table 1 Characteristics of Patient Visits to CHCs vs Private Practices, 2010-2012

\begin{tabular}{|c|c|c|c|}
\hline Characteristics & $\begin{array}{l}\text { CHC } \\
(n=11,905)\end{array}$ & $\begin{array}{l}\text { Private practices } \\
(n=17,250)\end{array}$ & $p$ Value \\
\hline $\begin{array}{l}\text { Weighted visits } \\
\text { (million) }\end{array}$ & 37.6 & 546.6 & \\
\hline Age (mean) & 50.7 & 56.4 & $<0.001$ \\
\hline Female sex $(\%)$ & 59.8 & 56.7 & 0.04 \\
\hline Race/ethnicity (\%) & & & $<0.001$ \\
\hline $\begin{array}{l}\text { Non-Hispanic } \\
\text { White } \\
\text { Non-Hispanic }\end{array}$ & 47.0 & 74.0 & \\
\hline African & & & \\
\hline American & 20.1 & 12.6 & \\
\hline Hispanic & 28.4 & 9.4 & \\
\hline Other & 4.6 & 3.9 & \\
\hline Insurance & & & $<0.001$ \\
\hline Medicaid & 31.7 & 10.0 & \\
\hline Medicare & 17.5 & 30.8 & \\
\hline Private & 15.5 & 49.0 & \\
\hline Uninsured & 19.6 & 4.9 & \\
\hline Other & 9.9 & 1.5 & \\
\hline Unknown & 5.9 & 3.8 & \\
\hline Comorbidities & & & 0.005 \\
\hline 0 & 15.1 & 17.5 & \\
\hline $1-2$ & 48.9 & 45.2 & \\
\hline $3-4$ & 31.0 & 29.5 & \\
\hline $5+$ & 5.0 & 7.8 & \\
\hline MSA & & & 0.210 \\
\hline Rural & 23.4 & 17.2 & \\
\hline Practice census region & & & $<0.001$ \\
\hline Northeast & 19.4 & 20.9 & \\
\hline Midwest & 15.5 & 23.8 & \\
\hline South & 30.7 & 37.0 & \\
\hline West & 34.5 & 18.3 & \\
\hline
\end{tabular}


Table 2 Unadjusted Rates of Performance Measures by Site of Care

\begin{tabular}{|c|c|c|c|}
\hline Performance measures (\%) & CHCs & Private practices & $p$ Value \\
\hline \multicolumn{4}{|l|}{ High-value care } \\
\hline Tobacco cessation counseling & $57.6(46.7,68.6)$ & $61.8(52.7,70.9)$ & 0.55 \\
\hline Weight reduction counseling & $34.0(28.3,39.8)$ & $30.0(26.7,33.4)$ & 0.24 \\
\hline Anticoagulant use in AFib & $68.7(55.7,81.8)$ & $59.3(51.7,66.9)$ & 0.25 \\
\hline Aspirin use in CAD & $43.5(31.9,55.1)$ & $40.3(34.6,45.9)$ & 0.64 \\
\hline $\mathrm{BB}$ use in CAD & $47.5(37.7,57.3)$ & $38.9(32.6,45.3)$ & 0.14 \\
\hline Statin use in CAD & $46.9(37.3,56.5)$ & $44.9(39.4,50.5)$ & 0.75 \\
\hline $\mathrm{BB}$ in $\mathrm{CHF}$ & $46.9(31.9,61.9)$ & $36.5(30.6,42.4)$ & 0.20 \\
\hline $\mathrm{ACEi} / \mathrm{ARB}$ in $\mathrm{CHF}$ & $44.1(28.8,59.3)$ & $31.6(25.8,37.4)$ & 0.13 \\
\hline Antiplatelet use in CVD & $31.8(17.6,46.0)$ & $35.2(28.9,41.5)$ & 0.70 \\
\hline Statin use in DM & $37.0(31.9,42.1)$ & $35.5(32.6,38.4)$ & 0.62 \\
\hline Treatment for depression & $50.6(46.1,55.0)$ & $51.9(49.5,54.4)$ & 0.58 \\
\hline Treatment for osteoporosis & $35.7(27.0,44.4)$ & $23.2(18.8,27.5)$ & 0.007 \\
\hline \multicolumn{4}{|l|}{ Low-value care } \\
\hline No screening EKG in GME & $98.7(97.4,99.9)$ & $88.0(84.2,91.8)$ & $<0.001$ \\
\hline No screening $\mathrm{CBC}$ in GME & $75.9(70.7,81.0)$ & $65.7(61.9,69.6)$ & 0.003 \\
\hline No screening UA in GME & $86.0(81.5,90.6)$ & $80.5(76.7,84.2)$ & 0.07 \\
\hline Antibiotics for URI & $48.3(40.9,55.6)$ & $63.1(58.2,68.0)$ & $<0.001$ \\
\hline Opioids for back/neck pain & $38.8(33.7,43.9)$ & $36.4(32.2,40.7)$ & 0.48 \\
\hline CT/MRI for back/neck pain & $4.9(3.1,6.7)$ & $5.2(4.2,7.0)$ & 0.53 \\
\hline Opioids for headache & $17.3(10.7,23.9)$ & $13.2(9.9,16.5)$ & 0.26 \\
\hline
\end{tabular}

\begin{tabular}{|l|l|}
\hline High-Value Care & $\begin{array}{l}\text { Adjusted OR } \\
(\mathbf{9 5 \%} \text { Cl) }\end{array}$ \\
\hline $\begin{array}{l}\text { Tobacco } \\
\text { cessation } \\
\text { counseling }\end{array}$ & $\begin{array}{l}1.24 \\
(0.70,2.20)\end{array}$ \\
\hline $\begin{array}{l}\text { Weight reduction } \\
\text { counseling }\end{array}$ & $\begin{array}{l}1.08 \\
(0.74,1.58)\end{array}$ \\
\hline $\begin{array}{l}\text { Anticoagulant use } \\
\text { in AFib }\end{array}$ & $\begin{array}{l}1.77 \\
(0.65,4.85)\end{array}$ \\
\hline $\begin{array}{l}\text { Aspirin use in } \\
\text { CAD }\end{array}$ & $\begin{array}{l}1.12 \\
(0.61,2.04)\end{array}$ \\
\hline BB use in CAD & $\begin{array}{l}1.75 \\
(0.99,3.12)\end{array}$ \\
\hline Statin use in CAD & $\begin{array}{l}1.70 \\
(0.99,2.92)\end{array}$ \\
\hline BB use in CHF & $\begin{array}{l}2.56 \\
(1.18,5.56)\end{array}$ \\
\hline $\begin{array}{l}\text { ACEi/ARB use in } \\
\text { CHF }\end{array}$ & $\begin{array}{l}1.98 \\
(0.97,4.07)\end{array}$ \\
\hline $\begin{array}{l}\text { Antiplatelet use in } \\
\text { CVD }\end{array}$ & $\begin{array}{l}0.85 \\
(0.39,1.87)\end{array}$ \\
\hline Statin use in DM & $\begin{array}{l}1.35 \\
(1.02,1.79)\end{array}$ \\
\hline $\begin{array}{l}\text { Treatment for } \\
\text { depression }\end{array}$ & $\begin{array}{l}1.08 \\
(0.84,1.39)\end{array}$ \\
\hline $\begin{array}{l}\text { Treatment for } \\
\text { osteoporosis }\end{array}$ & $\begin{array}{l}1.77 \\
(1.05,3.00)\end{array}$ \\
\hline
\end{tabular}

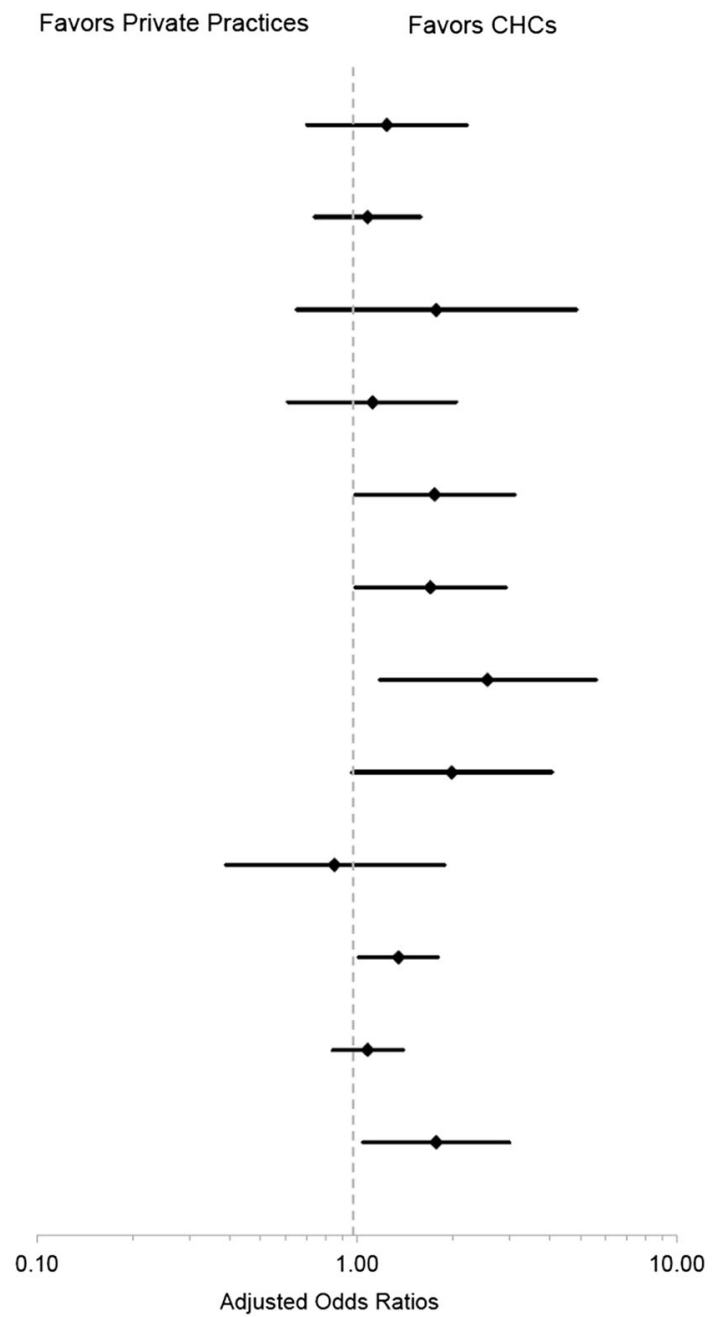

Fig. 1 Adjusted odds ratios of high-value care measures by site of care. OR is adjusted odds ratio for receipt of high-value care with private practices as the reference group. GME is general medical exam; BB is beta-blocker; ACEi is angiotensin-converting enzyme inhibitor; ARB is angiotensin receptor blockers. 
more likely to prescribe beta-blockers at visits for CHF ( $\mathrm{aOR}$ 2.56; 95\% CI 1.18, 5.56), prescribe statins in DM (aOR 1.35; $95 \%$ CI $1.02,1.79$ ) and provide treatment for osteoporosis (aOR $1.77 ; 95 \%$ CI 1.05, 3.00) compared with private practices. Figure 2 demonstrates the provision of low-value care by $\mathrm{CHCs}$ and private practices. CHCs were more likely to avoid screening UAs in general medical exams (aOR 1.87, 95\% CI 1.11-3.14), screening EKGs (aOR 11.03; 95\% CI 2.67, 45.52), and CBCs (aOR 1.72; 95\% CI 1.18, 2.53). CHCs were also less likely to prescribe antibiotics for URIs (aOR 0.59; $95 \%$ CI 0.40, 0.88; Fig. 2).

\section{DISCUSSION}

In this national study, community health centers were associated with the delivery of more high-value services and fewer low-value services compared with private practices. Lowvalue care includes medical services for which the potential for harm exceeds the potential benefits or the benefits are unclear. Optimizing high-value services while limiting the provision of low-value care offers the potential to improve quality while at the same time reducing costs, which is the focus of the national ABIM Choosing Wisely campaign. ${ }^{6}$
We found that CHCs were more likely to deliver high-value care compared with private practices in three clinical conditions. CHCs were more likely to prescribe beta-blockers in CHF, statins in diabetes, and pharmacologic treatment for osteoporosis. While they were also more likely to deliver high-value care compared with private practices on nearly all other measures, these results were not statistically significant. The greater provision of high-value care may be related to multiple factors, including the organizational and policy advantages that $\mathrm{CHCs}$ have as a result of their unique position in the safety net. CHCs have access to collaborative learning partnerships and frequently engage in sustained quality improvement initiatives. ${ }^{22}$ In fact, a prior study examining a national program to improve cardiovascular preventative care found that $\mathrm{CHCs}$ had considerably higher rates of participation in quality improvement initiatives compared with physicianowned practices. ${ }^{23}$ Similarly, some evidence suggests that CHCs may be more likely to escalate care for chronic conditions, like uncontrolled hypertension, compared with private practices. $^{24}$

During the same time period as our study, there was a concerted national effort to reform healthcare delivery and certify FQHCs as patient-centered medical homes (PCMH). $\mathrm{PCMH}$ adoption was, in turn, associated with improvements

Figure 2. Adjusted Odds Ratios of Low-Value Care Measures by Site of Care

\begin{tabular}{|l|l|}
\hline Low-Value Care: & $\begin{array}{l}\text { Adjusted OR } \\
(\mathbf{9 5 \%} \text { Cl) }\end{array}$ \\
\hline $\begin{array}{l}\text { Avoidance of } \\
\text { screening EKG in } \\
\text { GME }\end{array}$ & $\begin{array}{l}11.03 \\
(2.67,45.52)\end{array}$ \\
\hline $\begin{array}{l}\text { Avoidance of } \\
\text { screening CBC in } \\
\text { GME }\end{array}$ & $\begin{array}{l}1.72 \\
(1.18,2.53)\end{array}$ \\
\hline $\begin{array}{l}\text { Avoidance of } \\
\text { screening UA in } \\
\text { GME }\end{array}$ & $\begin{array}{l}1.87 \\
(1.11,3.14)\end{array}$ \\
\hline & $\begin{array}{l}0.59 \\
(0.40,0.88)\end{array}$ \\
\hline Antibiotics for URI & $\begin{array}{l}0.91 \\
(0.69,1.22)\end{array}$ \\
\hline $\begin{array}{l}\text { Opioids for } \\
\text { back/neck pain }\end{array}$ & $\begin{array}{l}1.06 \\
(0.61,1.84)\end{array}$ \\
\hline $\begin{array}{l}(0.37,1.48) \\
\text { bT/MRI for } \\
\text { back/neck pain }\end{array}$ \\
\hline $\begin{array}{l}\text { Opioids for } \\
\text { headache }\end{array}$ & \begin{tabular}{l}
0.74 \\
\hline
\end{tabular} \\
\hline
\end{tabular}

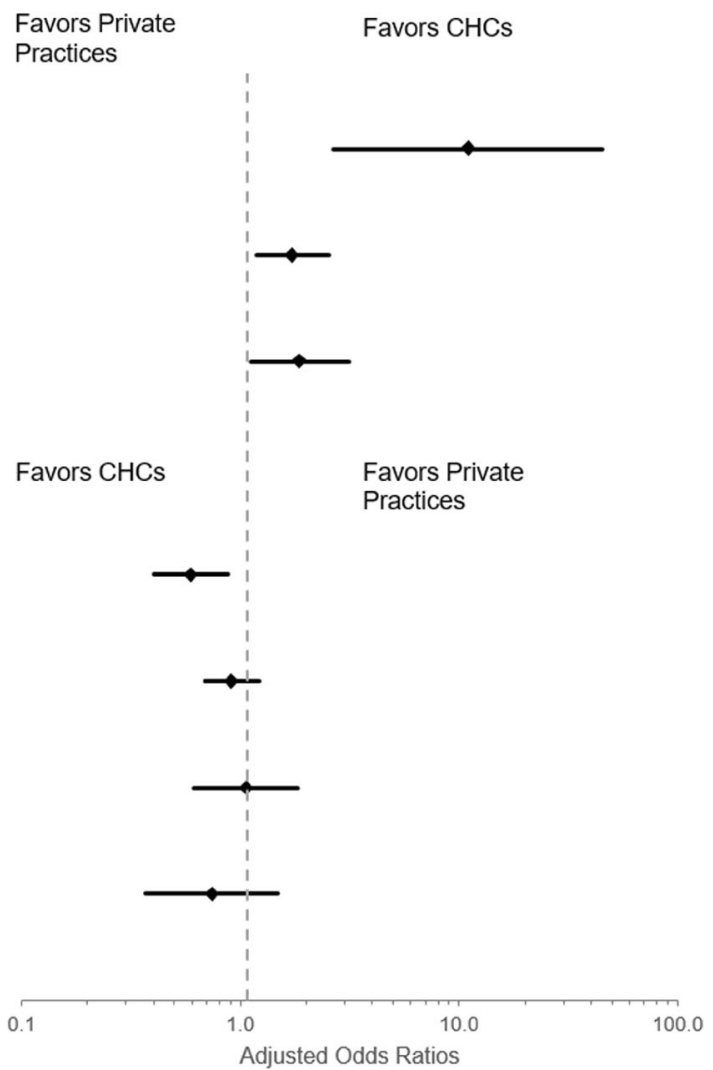

Fig. 2 Adjusted odds ratios of low-value care measures by site of care. OR is adjusted odds ratio for receipt of low-value care with private practices as the reference group. GME is general medical exam; OR for screening EKG in GME is truncated for visual ease. 
in FQHC quality. ${ }^{25-27}$ Implementation of a PCMH model involves investing in care coordination, new health information technology, and redesign of care processes with tracking of patient outcomes and quality. While not directly examined in our study, this broader adoption of the PCMH model among CHCs (41\% adoption in CHCs compared with $18 \%$ nationally) may explain the greater provision of high-value care at CHCs. $^{27,28}$

In addition to providing more high-value services, we found that CHCs were more likely to avoid low-value care, such as unnecessary antibiotic prescriptions for URIs and unnecessary screening tests, such as EKGs, UAs, and CBCs during a general exam, compared with private practices. CHCs performed similarly on other low-value measures including the use of opioids and advanced imaging for back and neck pain. Our results are consistent with prior work that demonstrated that $\mathrm{CHCs}$ were more likely to avoid screening EKGs. ${ }^{5} \mathrm{We}$ expand on the findings of this prior study, using recently characterized measures of low-value care to measure excess ordering of antibiotics, opioids, and advanced imaging.

Our findings differ slightly from a recent study that examined low-value care among broader safety net practices. In that analysis, safety net physicians were defined as those with a patient panel composed of at least 25\% Medicaid or uninsured patients. Compared with non-safety net physicians, there were no significant differences in the delivery of low-value screening tests, antibiotics for URI, opioids for back and neck pain, CT scan for sinusitis, or advanced imaging for headache. ${ }^{10}$ Safety net providers did have lower use of advanced imaging for back or neck pain. ${ }^{10}$ An important difference between our findings and the previous study that may explain our discordant results is the inclusion of hospital-based outpatient clinics. While safety net practices had a similar payer mix as our sample of CHCs, approximately $20 \%$ of safety net providers were hospital-based outpatient clinics, which may be associated with higher rates of low-value care. ${ }^{29}$ The ability of CHCs to limit low-value care may be related to the structural and organizational advantages previously described. Within encounters, physicians practicing at CHCs may be more likely to have conversations with their patients regarding the cost of care. ${ }^{30}$ As a result, clinicians at CHCs may be more sensitive to their patients' out-of-pocket costs and refrain from ordering unnecessary tests or prescribing unnecessary medications.

The broader implications of our work underscore the importance of CHCs for delivery system reform in general, and for care of underserved patient populations in particular. $\mathrm{Na}-$ tional healthcare reforms have begun to shift delivery systems away from fee-for-service payments toward value-based and alternative payment models. Similarly, many states have opted to participate in Medicaid waivers known as Delivery System Reform Incentive Programs. These waivers have been used to implement Medicaid accountable care organizations with varying degrees of financial risk, including fully capitated models. ${ }^{31}$ While there has been some concern that alternative payment models and value-based contracts may inadvertently exacerbate disparities by exposing CHCs to the risk of lower revenue, others have argued that such payment reform may lead to higher quality care and better outcomes. ${ }^{32}$ Our findings suggest that CHCs are positioned to perform well on the measures of high- and low-value care as payment reform expands among safety net health systems. However, caution must be exercised before drawing parallels to other clinical quality measures that might be more susceptible to patients' social determinants of health, such as ambulatory caresensitive admissions and all-cause 30-day readmissions. ${ }^{33}$ Further work will be needed to elucidate the specific processes and best practices used by $\mathrm{CHCs}$ that may be applicable to other health systems as they seek to maximize value.

There are a number of limitations to our work. First, the use of survey data is susceptible to issues with sampling error; however, we used standardized methods employed in prior studies using NAMCS in addition to using multiple years of data. Second, the measures in our study may have misattributed patients based on exclusion and inclusion criteria, but we constructed these measures based on professional society recommendations and prior literature regarding high- and low-value care. Additionally, our measurement is limited by what codes are documented on an individual visit. Last, while we controlled for multiple factors, there is the possibility that residual confounding may exist. Within the multivariable regression models, we adjusted for patient insurance, but future work should examine how differences in managed care penetration in Medicaid and high-deductible health plans among the commercially insured may explain the differences observed between $\mathrm{CHCs}$ and private practices. Furthermore, our cross-sectional analysis is unable to establish causality. Additional studies are needed to understand the operational best practices that may explain our findings and are generalizable to the larger environment of outpatient settings.

\section{CONCLUSION}

Maximizing quality and limiting services that provide marginal or unknown benefit to patients are increasingly recognized as key components of healthcare reform. Using nationally representative data, our work shows that $\mathrm{CHCs}$ exceeded the performance of private practices on several high-value and low-value care measures and were comparable on all others. As healthcare reforms and alternative payment models continue to expand across safety net practices, CHCs are well positioned to perform well on the measures of both highand low-value care.

Acknowledgments: Dr. Oronce was an internal medicine resident at the University of Rochester Medical Center at the time the study was completed. He is currently supported by the VA Office of Academic Affiliations through the VA/National Clinicians Scholars Program. 
Corresponding Author: Carlos Irwin A. Oronce, MD, MPH; National Clinician Scholars Program and the Division of General Internal Medicine and Health Services Research, University of California, 1100 Glendon Ave. Ste. 900, Los Angeles, CA 90034, USA (e-mail: COronce@mednet.ucla.edu).

Compliance with Ethical Standards:

Disclaimer: The contents do not represent the views of the U.S. Department of Veterans Affairs or the US Government.

Ethical Approval: The University of Rochester Research Subjects Review Board approved this study.

Conflict of Interest: The authors declare that they do not have a conflict of interest.

\section{REFERENCES}

1. Health Resources and Services Administration. HRSA Health Center Program. Available at: https://bphc.hrsa.gov/sites/default/files/bphc/ about/healthcenterfactsheet.pdf. Published 2018. Accessed September 26, 2019.

2. Rosenbaum S, Paradise J, Markus A, Sharac J, Tran C, Reynolds D Community Health Centers : Recent Growth and the Role of the ACA. Washington, DC; 2016.

3. American College of Physicians. High Value Care. Available at: https:// www.acponline.org/clinical-information/high-value-care. Accessed September 26, 2019.

4. Laiteerapong $\mathbf{N}$, Kirby $\mathbf{J}$, Gao $\mathbf{Y}$, et al. Health care utilization and receipt of preventive care for patients seen at federally funded health centers compared to other sites of primary care. Health Serv Res 2012;49(5):1498-1518. doi:https://doi.org/10.1111/1475-6773.12178

5. Goldman LE, Chu PW, Tran H, Romano MJ, Stafford RS. Federally qualified health centers and private practice performance on ambulatory care measures. Am J Prev Med 2012;43(2):142-149.

6. ABIM Foundation. Choosing Wisely: Promoting conversations between patients and clinicians. Available at: http://www.choosingwisely.org/. Accessed September 26, 2019

7. Wright B, Potter AJ, Trivedi AN. Use of federally qualified health centers and potentially preventable hospital utilization among older MedicareMedicaid enrollees. J Ambul Care Manage 2017:40(2):139-149. doi:https://doi.org/10.1097/JAC.0000000000000158

8. Falik M, Needleman J, Herbert R, Wells B, Politzer R, Benedict MB. Comparative effectiveness of health centers as regular source of care: Application of sentinel ACSC events as performance measures. $J$ Ambul Care Manage 2006;29(1):24-35. doi:https://doi.org/10.1097/00004479200601000-00004

9. Gurewich D, Tyo KR, Zhu J, Shepard DS. Comparative performance of community health centers and other usual sources of primary care. $J$ Ambul Care Manage 2011;34(4):380-390. doi:https://doi.org/10.1097/ JAC.0b013e31822cbc59

10. Barnett ML, Linder JA, Clark CR, Sommers BD. Low-value medical services in the safety-net population. JAMA Intern Med 2017;177(6):829837. doi:https://doi.org/10.1001/jamainternmed.2017.0401

11. Health Resources \& Services Administration. Health Center Program Compliance Manual. Washington, DC; 2018. Available at: https://bphc. hrsa.gov/programrequirements/compliancemanual/chapter-3.html. Accessed September 26, 2019.

12. National Center for Health Statistics. NCHS public-use data files and documentation: National Ambulatory Medical Care Survey (NAMCS)-2010, 2011，2012. Available at: ftp://ftp.cdc.gov/pub/ Health_Statistics/NCHS/Dataset_Documentation/NAMCS. Accessed September 26, 2019.

13. Ma J, Stafford RS. Quality of US outpatient care: temporal changes and racial/ethnic disparities. Arch Intern Med 2005; 165(12):1354-1361.

14. Linder JA, Bates DW, Middleton B, et al. Electronic health record use and the quality of ambulatory care in the United States. JAMA Intern Med 2007;167(13):1400-1405. doi:https://doi.org/10.1001/archinte.167.13. 1400

15. Edwards ST, Mafi JN, Landon BE. Trends and quality of care in outpatient visits to generalist and specialist physicians delivering primary care in the United States, 1997-2010. J Gen Intern Med 2014;29(6):947955. doi:https://doi.org/10.1007/s11606-014-2808-y

16. Kale MS, Bishop TF, Federman AD, Keyhani S. Trends in the overuse of ambulatory health care services in the United States. JAMA Intern Med
2013;173(2):142-148. doi:https://doi.org/10.1001/2013. jamainternmed. 1022

17. Mehrotra A, Gidengil CA, Setodji CM, Burns RM, Linder JA. Antibiotic prescribing for respiratory tract infections at retail clinics, physician practices, and emergency departments. Am $J$ Manag Care 2015;21(4):294-302. doi:https://doi.org/10.1370/afm.1090. INTRODUCTION

18. Mafi JN, Edwards ST, Pedersen NP, Davis RB, McCarthy EP, Landon BE. Trends in the ambulatory management of headache: analysis of NAMCS and NHAMCS data 1999-2010. J Gen Intern Med 2015;30(5):548-555. doi:https://doi.org/10.1007/s11606-014-3107-3

19. Mafi JN, McCarthy EP, Davis RB, Landon BE. Worsening trends in the management and treatment of back pain. JAMA Intern Med 2013;173(17):1573-1581. doi:https://doi.org/10.1001/jamainternmed. 2013.8992

20. Mehrotra A, Zaslavsky AM, Ayanian JZ. Preventive health examinations and preventive gynecological examinations in the United States. Arch Intern Med 2007;167(17):1876-1883. doi:https://doi.org/10.1001/ archinte.167.17.1876

21. National Center for Health Statistics. Using ultimate cluster models with NAMCS and NHAMCS public use files. Available at: https://www.cdc. gov/nchs/data/ahcd/ultimatecluster.pdf. Published 2004. Accessed September 26, 2019.

22. Chin MH, Drum ML, Guillen M, et al. Improving and sustaining diabetes care in community health centers with the health disparities collaboratives. Med Care 2007;45(12):1135-1143. doi:https://doi.org/10. 1097/MLR.0b013e31812da80e

23. Lindner S, Solberg LI, Miller WL, et al. Does Ownership Make a Difference in Primary Care Practice? $J$ Am Board Fam Med 2019;32(3):398-407. doi:https://doi.org/10.3122/jabfm.2019.03. 180271

24. Fontil V, Bibbins-Domingo K, Nguyen OK, Guzman D, Goldman LE. Management of hypertension in primary care safety-net clinics in the United States: a comparison of community health centers and private physicians' offices. Health Serv Res 2017;52(2):807-825. doi:https://doi. org/10.1111/1475-6773.12516

25. Shi $\mathbf{L}$, Lock DC, Lee DC, et al. Patient-centered medical home capability and clinical performance in HRSA-supported health centers. Med Care 2015;53(5):389-395. doi:https://doi.org/10.1097/MLR. 0000000000000331

26. Shi L, Lee D-C, Chung M, Liang $\mathbf{H}$, Lock D, Sripipatana A. Patientcentered medical home recognition and clinical performance in U.S. community health centers. Health Serv Res 2017;52(3):984-1004. doi:https://doi.org/10.1111/1475-6773.12523

27. Hu R, Shi L, Sripipatana A, et al. The association of patient-centered medical home designation with quality of care of HRSA-funded health centers: a longitudinal analysis of 2012-2015. Med Care 2018;56(2):130138. doi:https://doi.org/10.1097/MLR.0000000000000862

28. Hing E, Kurtzman E, Lau DT, Taplin C, Bindman AB. Characteristics of primary care physicians in patient-centered medical home practices: United States, 2013. Natl Health Stat Report 2017;(101).

29. Mafi JN, Wee CC, Davis RB, Landon BE. Association of primary care practice location and ownership with the provision of low-value care in the United States. JAMA Intern Med 2017;177(6):838-845. doi:https:// doi.org/10.1001/jamainternmed.2017.0410

30. Tipirneni R, Patel MR, Kirch MA, Goold SD. Cost conversations between primary care providers and patients with expanded Medicaid coverage. J Gen Intern Med 2018;33(11):1845-1847. doi:https://doi.org/ 10.1007/s11606-018-4551-2

31. McConnell KJ, Renfro S, Chan BKS, et al. Early performance in Medicaid accountable care organizations a comparison of Oregon and Colorado. JAMA Intern Med 2017;177(4):538-545. doi:https://doi.org/ 10.1001/jamainternmed.2016.9098

32. Bhatia $\mathbf{J}$, Tobey $\mathbf{R}$, Hochman $\mathbf{M}$. Value-based payment models for community health centers. JAMA. 2017;317(22):2275-2276. doi:https:// doi.org/10.1001/jama.2017.5174

33. Roberts ET, Zaslavsky AM, Mcwilliams JM. The value-based payment modifier: Program outcomes and implications for disparities. Ann Intern Med 2018;168(4):255-265. doi:https://doi.org/10.7326/M17-1740

Publisher's Note: Springer Nature remains neutral with regard to jurisdictional claims in published maps and institutional affiliations. 